\title{
An Overview of Attendance and Participation in Online Class During the COVID Pandemic: A Case Study
}

\author{
https://doi.org/10.3991/ijim.v16i04.27103 \\ Duha Qutishat $^{(\varpi)}$, Randa Obeidallah, Yasser Qawasmeh \\ Faculty of Prince Al-Hussein Bin Abdallah II For Information Technology, \\ The Hashemite University, Zarqa, Jordan \\ duha@hu.edu.jo
}

\begin{abstract}
COVID-19 pandemic had transformed traditional learning in schools and universities into online classrooms. Monitoring students' attendance and interaction during live online classes is a challenge for educators. During the lockdown, many factors had influenced attendance and participation in online classes. In this paper, the course Introduction to web programming lab is considered a case study to investigate the participation of students in programming labs at Hashemite University. This descriptive and quantitative research included 212 students in the academic year (2020/2021). Students' participation had been observed and collected based on records of attendance sheets, in-class interaction, assignment delivery, and utilization of e-learning platforms. Data were also collected through a survey to measure student satisfaction of delivering course learning outcomes (CLOs). Qualitative interviews were conducted to emphasize factors that affected participation and interaction in online class; such factors include Hardwar/Software issues, psychological/ environmental issues, and financial issues. Findings also showed that online education was successfully implemented. However, the interaction of students during meeting class is considered below average. Attendance and performance data were analyzed using correlation analysis and showed a weak positive relationship.
\end{abstract}

Keywords - online-classrooms, participation, interaction, attendance, programming lab, course learning outcome, e-learning platform, student, e-learning, virtual learning, distance learning

\section{Introduction}

Online learning is divided into two main areas: learning and technology [3]. Learning is the cognitive process for achieving knowledge, and technology is the tool to support that process. Nowadays, the digital world is continuously improving to allow people to access internet websites, mobile applications and use different technology tools for work, education and entertainment.

As a result of the Covid-19 pandemic, the traditional work and learning process had shifted into the sudden usage of online platforms [26-28]. Continuous education is needed even during catastrophic periods, and therefore, online programs are now a 
requirement. Teaching and learning processes must be redesigned to adhere to social distance norms [29]. The educational system (administration, teacher, and student) dealt with rapid learning change. The experience of using technology is a primary reason that made both teachers and students familiar with e-learning [4] [18].

E-learning benefits from studying anywhere, anytime, with minimum cost [21]. The availability of different platforms of online simulator tools and applications has helped teachers deliver theoretical and practical knowledge to students and helped students understand the context [30].

In traditional classrooms, attendance is positively associated with academic progress [15]. The lecturer may have more influence over engaging students and minimizing distractions. While in online classes where there is no direct contact, students may not be influenced and engaged for extended lengths of time if they are taught online. During live sessions, they are easily distracted and lose concentration. In order to simulate the efficiency of traditional classes, online educators must promote the social side of learning.

It is essential to highlight; that attending the class and interacting to learn the course are two different issues. Ensuring students' participation rather than just an attendee in the underlying course will influence their satisfaction and motivation to accomplish its intended goals. Student interaction is one factor that improves the educational quality [20]. The lack of interaction leads to isolation among students [20]. In distance/online learning context, educators may be familiar with the tremendous development in online learning implementation, but they must understand how students perceive, access, and react to it in addition to the level of commitment [1]. The lack of interaction among students leads to dissatisfaction [17][23]. Many studies investigated the usage of technologies to encourage engagement and participation in an online environment, creating a series of tools that enable learners to actively participate in live sessions to recreate the feeling of community in the virtual world [9][14].

Like the rest of the world, the government of Jordan had suspended teaching activities at the beginning of the 15th of March 2020. During the Covid-19 lockdown, the Hashemite university had adapted the online delivery of all courses to students. In this study, we will take the online course" Introduction to Web Programming Lab" as a case study to measure the participation and interaction of students during the academic year 2020/2021. The research was carried out in the spring/autumn semesters of 2020-2021 for the Introduction to Web Programming Lab course at Hashemite University. Two hundred twelve students are involved in this study. Several methodologies were applied to collect and analyze data. Attendance files were collected manually and analyzed. A five-point scale survey was distributed to measure the satisfaction of delivery of course learning outcome and finally, a qualitative interview with students to identify factors the affected the learning process.

Further analysis is applied to find factors that affect interaction during an online class. A correlation analysis is performed to find a relationship between attendance and students' academic records. In this research, we will attempt to answer the following questions:

- Do students attend online classes regularly as in traditional classes?

- How are students' performance and interaction in online classes is measured? 
- Are students satisfied with delivering course learning outcomes during online classes?

- Is there any relationship association between attendance and academic performance?

- Furthermore, what are the Challenges and factors that affect the participation of students?

This paper is structured as follows: Section 2 is a brief background that highlights the attendance and participation of students in virtual classes. Section 3 describes the Teaching Methodology in Introduction to Web Programming Lab as an online class, and section 4 introduces the research methodology. Results and discussions are given in section 5. Factors that affected students' participation are introduced in section 6. Finally, the conclusion is in section 7.

\section{Background}

School attendance is usually mandatory and recorded manually by the teacher or automated systems. In traditional classrooms, the teacher's tracking process is accomplished manually. During the lecture, the teacher reads students' names within the attendance sheet or passes the attendance sheet to students and asks them to sign beside their names. This process consumes time, and it is considered inapplicable in classes containing over 50 students.

Many automated attendance systems would help teachers monitor students' attendance. Systems are usually classified into either RFID/NFC-based that use installed readers with RFID cards or codes or visual-based methods that apply biometric recognition algorithms [11].

Many researchers implemented and provided automated attendance systems as stated in [6][25] who used RFID with specific readers (device) to be installed in the classroom and connected to the internet. Oktavianto [16] proposed a real-time video analysis system for logging attendance. [11] designed and implemented an automated attendance tracking system using smartphones that integrate voiceprint biometrics with the real-time location.

Many universities use Learning Management Systems (LMS) such as Moodle that provides a feature to record all students who enter the course material and print the result as a report. This feature is also available in Microsoft Teams; the report indicates student Id, name, time of entering the live meeting, and connection duration.

Due to the pandemic, new attendance regulations were developed by universities to keep the process of learning monitored and activated. One of the significant challenges in online learning during the covid-19 lockdown is monitoring students' attendance and engagement during online classes. It is essential to highlight that attending the class and interacting to learn the course material are two different issues, as stated in [22], which focused on the attention and attendance problems faced during online classes. The results showed that nearly $62 \%$ of students lose interest in the class. The authors suggested solving the problem of attendance using facial recognition.

The academic environment is usually measured by monitoring students' academic performance, attendance, and interaction within the classroom. Researchers showed 
that there is a strong relevance between students' class attendance and academic performance [8][10][24]. A study made by [24] showed that increased attendance does improve academic performance. Students who attend the class tend to understand the course material and are interested in the topic covered in class, usually performing better in class. Meanwhile, several studies showed that recording lectures in blended learning and uploading to the internet had reduced student attendance and affected the academic record [7][19].

Ozaydın [17] studied factors that influence student participation in an online environment from the students' perspective, where 15 students worked collaboratively, and 15 students worked independently. Interviews and reflection reports were used to gather data and found that students tended to have a good attitude about remote learning but found it more motivating to have the opportunity to communicate face-to-face.

Midgley and Resalat [14] showed that different online platforms enhanced the interaction between students and teachers. Online platforms allow students to track course information and get involved via written comments, audio, and video. Social networks also play a tremendous role in allowing students to communicate [5]. Social networks are the trend for collaboration and participation in the learning process [13].

\section{Case study: introduction to web programming lab as an online class}

Like the rest of the world, the government of Jordan had suspended teaching activities at the beginning of the 15th of March 2020. During the Covid-19 lockdown, the Hashemite university had adapted the online delivery of all courses materials to students. One of the programming labs shifted to an online course is the Introduction to Web Programming Lab. This lab is a mandatory course for all computer Information system students, and it is considered the practical part of the theoretical course Introduction to Web Programming. This course is taught for two hours weekly. Introduction to Web Programming formerly titled HTML5, CSS, Javascript, and PHP.

During the Covid-19 lockdown, the class Introduction to Web Programming was given two hours every week. A real-time meeting was held, with the first half dedicated to introducing and discussing the topic at hand using real-time coding examples. The second part allows students to apply the new understudy concept and share their work with the instructor via screen sharing or taking screenshots to the final result and sending it via chat dialog under the lab instructor's guidance.

Participants were given a variety of activities, with particular attention made to guarantee students' self-discipline in terms of both the online lecture's actual existence and their degree of understanding. This was accomplished by employing short popup quizzes at the end of several lectures to assess understanding in real-time and boost students' motivation throughout the course by staying focused, reducing distractions, and earning extra credit.

In addition to real-time meetings and instant coding, teachers presented extra lectures to provide students with a new question based on a previously discussed topic with limited time. The main goal is to increase students' enthusiasm throughout the learning process with competition or collaboration between class team members. 
Students were given a link to a Facebook group with the course name and semester understudy for rapid feedback and online chats. Embedding social media as part of the transition to an online course has demonstrated several benefits, including allowing students from various sections to exchange solutions and concepts covered throughout the course, collaborate on a challenging programming exercise as a fun activity rather than a mandatory task, as well as discuss and analyze the held exams.

\section{$4 \quad$ Methodological framework}

\subsection{Data collection and data analysis}

This study is descriptive research. Quantitative data were collected using three different ways. Firstly: Quantitative observations data were mainly collected from the attendance report that is available as a feature in Microsoft Teams. The report was downloaded and examined for every lecture in the academic year 2020/2021. The extracted excel file contains all participant information, including meeting joining time and date and student left time, which was utilized to determine students' attendance. We also manually observed and gathered the number of students who could deliver solutions for the lab sheet examples and interact during lecture time.

Secondly, Qualitative data was conducted through interviewing students to determine factors that affected students' participation during online classes. Open-ended questions were analyzed and categorized in this collective case study.

Thirdly; A 5-point Likert self-assessment online survey included four questions to address the efficiency of delivering course learning output (CLOs) in online classes. This evaluation was made on a five-point scale that included (Strongly Agree, Agree, Neutral, Disagree, and Strongly Disagree).

Data were validated after removing responses from students who dropped the course and withdrew it. The total number of students who responded to the survey was 212 students. It is essential to mention that every course in the faculty of Information Technology has an automated method that allows students to evaluate the registered courses in terms of Course Learning and Outcomes CLOs at the end of every semester. The survey is distributed to students via the student portal. Course learning outcomes for the Introduction to Web Programming Lab course (CLOs) are shown in Table 1.

The final result is calculated by multiplying the number of students in each measurement scale by a weight value ranging from 5 for strongly agree to 1 for strongly disagree, as shown in the following equation:

$$
\begin{aligned}
\text { Average CLO }= & (\text { count }(\text { Strongly Agree }) * 5+\text { count }(\text { Agree }) * 4 \\
& + \text { count }(\text { Neutral }) * 3+\text { count }(\text { Disagree }) * 2 \\
& + \text { count }(\text { Strongly Disagree }) * 1) / \text { count }(\text { class })) / 5 .
\end{aligned}
$$

Where count indicates the number of students who answered the underlying assessment measure. 
Table 1. Survey: course learning outcomes (CLOs)

\begin{tabular}{|c|c|c|c|c|c|c|}
\hline & CLO Description & $\begin{array}{c}\text { Strongly } \\
\text { Agree }\end{array}$ & Agree & Neutral & Disagree & $\begin{array}{l}\text { Strongly } \\
\text { Disagree }\end{array}$ \\
\hline CLO 1 & $\begin{array}{l}\text { Design and implement } \\
\text { client-side applications } \\
\text { using HTML }\end{array}$ & & & & & \\
\hline CLO 2 & $\begin{array}{l}\text { Apply formatting styles } \\
\text { using the Cascading } \\
\text { Style Sheets on HTML } \\
\text { documents. }\end{array}$ & & & & & \\
\hline CLO 3 & $\begin{array}{l}\text { Install and configure } \\
\text { the Apache server and } \\
\text { MYSQL database. }\end{array}$ & & & & & \\
\hline $\mathrm{CLO} 4$ & $\begin{array}{l}\text { Access and manipulate } \\
\text { data through client- } \\
\text { side and server-side } \\
\text { programming. }\end{array}$ & & & & & \\
\hline
\end{tabular}

\section{$5 \quad$ Results and discussion}

The results of this research emphasize the following essential topics that this research aim to focus on:

- Class Attendance: Data from attendance records sheets were evaluated and examined to determine the percentage of attendance for the semesters under consideration and the association between attendance and academic performance.

- Participation/Interaction: Students were asked to solve several programming questions based on the material discussed during the underlying lectures to measure their interaction and assignment delivery. This process indicates the level of participation throughout the class, and an extra mark could be added to increase students' motivation to participate in class. A comparison was made to indicate the difference between the attendance percentage, which reflects the percentage of students who joined the meeting, and the participation percentage, which reflects the percentage of students who kept involved in the meeting rather than just joining the process.

- Course delivery satisfaction: The survey data involving CLOs was analyzed using an assessment survey to determine the percentage of students who were satisfied with the course learning outcomes of the Introduction to Web Programming Lab course.

\subsection{Students' participation and interaction}

As previously stated, data were collected online and analyzed in Microsoft Excel by downloading an excel summary file from Microsoft Teams that contained all participant information, including meeting joining time and date and student departure time, which was used to determine actual/physical attendance. 
As you can see, the average attendee level for both the first and second semesters of the academic year 2020-2021, which were online, was roughly $63.82 \%$ percent. This represented a $3.67 \%$ percent improvement over the first semester and a significant improvement over the previous year's second semester, a hybrid semester due to the online changeover occurring in the middle of the semester. We can deduce that students have become more familiar with online platforms. However, due to some of the issues that may arise, as we shall explore in the next part, it is still not as good as conventional on-campus classes.

Table 2. Student's attendance comparison

\begin{tabular}{|l|c|c|c|c|}
\hline \multicolumn{1}{|c|}{ Academic Year } & \multicolumn{2}{|c|}{ 2019-2020 } & \multicolumn{2}{c|}{ 2020-2021 } \\
\hline \multicolumn{1}{|c|}{ Semester } & 1st Semester & 2nd Semester & 1st Semester & 2nd semester \\
\hline Number of students & 144 & 106 & 112 & 100 \\
\hline Attendance & $85 \%$ & $54.55 \%$ & $61.99 \%$ & $65.66 \%$ \\
\hline
\end{tabular}

To distinguish the level of student interaction rather than just their attendance and as part of the online enhancement process, we distinguish between attendance and participation in the second semester. A coding question was given to students at the end of each class. This is because some students tend to join the meeting with no full attention to the course under discussion, and we are unable to ask students to turn on their video cameras due to connection and bandwidth instability issues.

According to the findings, $40 \%$ of students maintain contact and demonstrate some self-discipline, compared to over $85 \%$ in traditional on-campus classes, as presented in Table 2 and Table 3. The percentage of interaction among students during the meeting class is low, as clarified in Figure 1.

Table 3. Student's interaction comparison

\begin{tabular}{|l|c|c|}
\hline \multicolumn{1}{|c|}{ Academic Year } & \multicolumn{2}{c|}{ 2020-2021 } \\
\hline \multicolumn{1}{|c|}{ Semester } & 1st Semester & 2nd semester \\
\hline Number of students & 112 & 100 \\
\hline Participation/interaction & $40.85 \%$ & $39.64 \%$ \\
\hline
\end{tabular}

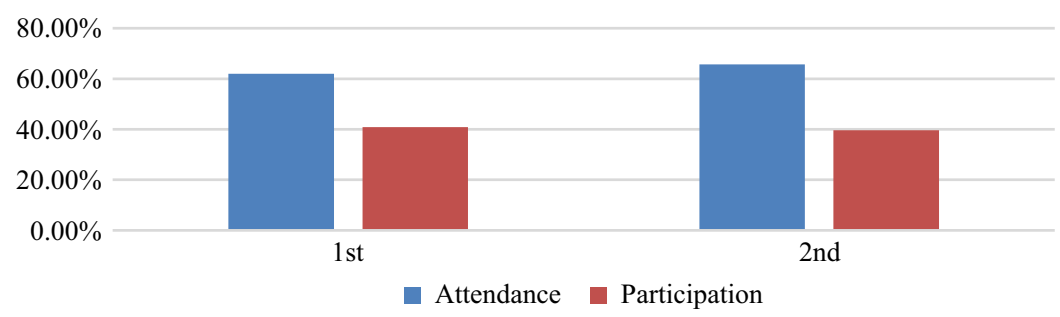

Fig. 1. Students attendance vs. interaction 


\subsection{Students' satisfaction}

Teachers of this lab had fully engaged in discussions with students, answered their questions, and provided them with the required assistance. Teachers were also actively providing feedback on the issues addressed in the student's assignments. In order to imitate a traditional on-campus class, students were allowed to submit their solutions for each worksheet at the end of each lecture, even if the meeting had ended, so that the instructor could supplement them with essential feedback and correct any faults that had occurred.

Students' satisfaction was measured by analyzing the results of a five-point scale survey of the four key course outcomes (Table 1) that aimed to cover the material's contents and asking students if the mentioned outcomes were addressed throughout the online course. The final result is calculated by multiplying the number of students in each measurement scale by a weight value ranging from 5 for strongly agree to 1 for strongly disagree, as shown in the following equation:

$$
\begin{aligned}
\text { Average CLO }= & (\text { count }(\text { Strongly Agree }) * 5+\text { count }(\text { Agree }) * 4 \\
& + \text { count }(\text { Neutral }) * 3+\text { count }(\text { Disagree }) * 2 \\
& + \text { count }(\text { Strongly Disagree }) * 1) / \text { count }(\text { class })) / 5 .
\end{aligned}
$$

where count indicates the number of students who answered the underlying assessment measure.

According to the findings of the comprehensive direction, Table 4 indicates that $83.3 \%$ of students who studied Introduction to Web Programming Lab in the second semester are satisfied with the course delivery of material content presented by the teacher during the online class. $80.16 \%$ of students in the first semester showed relatively equivalent results.

Table 4. CLOs comparison

\begin{tabular}{|l|c|c|}
\hline \multirow{2}{*}{ Course Learning Outcomes (CLOs) } & \multicolumn{2}{|c|}{$\mathbf{2 0 2 0 / 2 0 2 1}$ Academic Year } \\
\cline { 2 - 3 } & 1st Semester & 2nd Semester \\
\hline CLO1 & $81.88 \%$ & $85.07 \%$ \\
\hline CLO2 & $81.88 \%$ & $85.35 \%$ \\
\hline CLO3 & $78.44 \%$ & $81.41 \%$ \\
\hline CLO4 & $78.44 \%$ & $81.69 \%$ \\
\hline Average & $80.16 \%$ & $83.38 \%$ \\
\hline
\end{tabular}

\subsection{Students' attendance and academic performance}

Correlation analysis was applied to investigate the link between students' academic performance and attendance during online classes and a relationship between overall attendance and students' performance compared to the traditional classroom before the Covid-19 lockdown.

This study measures students' performance by performing tests, quizzes, homework, and exams. This is used to determine how well each student is doing in class. The scale 
of grading is from 0 to 100 . The total number of points a student had earned throughout the course is understudy, and we used the course grade out of 100 . On the other hand, the attendance was measured by recording the number of times each student had attended the class out of 32 classes, excluding four classes for exams purposes; therefore, the total number of classes is out of 28 classes.

Table 5 shows the percentage of students who received an $\mathrm{A}+, \mathrm{A}$, or $\mathrm{A}$ - grade and the average attendance of $88.67 \%$ and $86.677 \%$ from the total number of lectures. The findings add to the body of research about how attendance affects students' performance in higher education institutions in general.

Table 5. Student's attendance vs. examination performance

\begin{tabular}{|l|c|c|}
\hline \multicolumn{1}{|c|}{ Academic Year } & \multicolumn{2}{|c|}{ 2020-2021 } \\
\hline \multicolumn{1}{|c|}{ Semester } & 1st Semester & 2nd Semester \\
\hline $\begin{array}{l}\text { The percentage of students with grades } \\
(\mathrm{A}+, \mathrm{A}, \text { and A-) }\end{array}$ & $19.64 \%$ & $14 \%$ \\
\hline Attendance (Mean) & & $86.67 \%$ \\
\hline
\end{tabular}

After applying Pearson Correlation Coefficient Calculator to the data, the results showed a weak positive correlation and association between attendance and performance records, as shown in Figure 2. The value of $\mathrm{R}$ is 0.3404 , and the value of $\mathrm{R}^{2}$, the coefficient of determination, is 0.1159 . This means there is a positive correlation, but the relationship between the variables is weak. The nearer the value is to zero, the weaker the relationship.

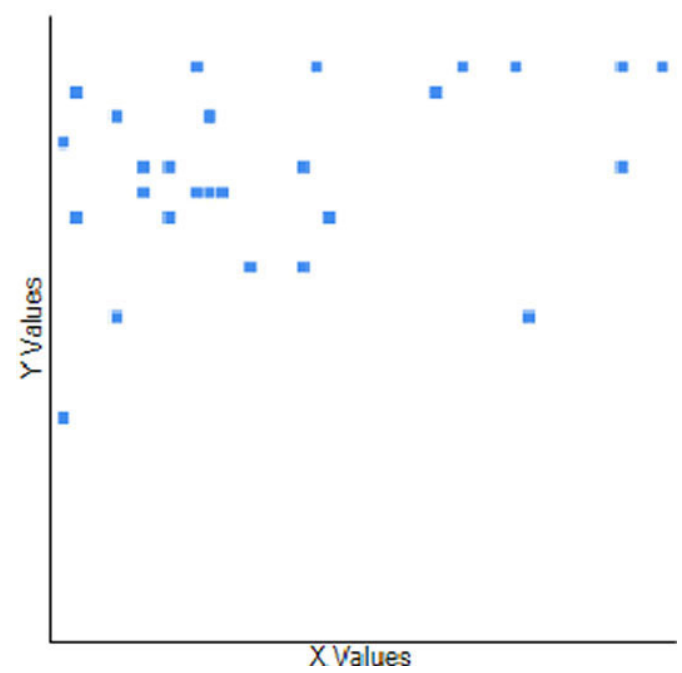

Fig. 2. Correlation relationship between (X values: represent students marks out of 100) and (Y values: represent the number of class attendance for each student out of 28 classes) 


\section{Factors affected students' participation}

Many obstacles exist during the online transferring process, such as the limitation of social interaction and the lack of commitment, with a great deal of distraction [12]. Students in rural areas face technological accessibility, poor internet connectivity, and challenging study environments [2].

According to an interview with the selective number of students who showed a total commitment during the semester, Qualitative data was examined and explored to categorize factors and issues that affected the participation and interaction of students during online classes. The factors are categorized as follows:

1. Network issues: The students' responsiveness to real-time classes improved with time, but network issues remained their primary concern. Because enormous amounts of data are transmitted during online classes, the network connection must be steady.

2. Device compatibility: Cell phones were more ordinary for students to access meetings of online courses rather than computers. However, mobile phones have restrictions regarding RAM capacity, features, and performance, making them unsuitable for IT students when a primary application needs to be installed. Laptops with appropriate requirements allow students to join online classes and implement the necessary code.

3. Environmental issues: The study environment plays a vital role in interacting during a class meeting. There are more distractions than usual while studying from home or the workplace. During the lockdown, all family members are also inside the house, distracting students from the class.

4. Psychological issues: lack of motivation, time management, Sense of Isolation, Adaptability Struggle, and lack of communication. In addition, sometimes instructors tend to give students more assignments to ensure their involvement than what we are given in conventional on-campus classes, which require more time management. Moreover, the stress of the unstable instructions across the country because of Covid-19.

5. Financial issues: many people lost their jobs during the lockdown and could not pay for the internet service provider or university fees. This caused anxiety and concerns for the future and caused for lack of concentration during online classes.

\section{Conclusion}

Online learning was a key factor during the Covid-19 lockdown to keep teaching and learning activities continuing. It is not easy for students and teachers to cope with online learning as they identify restrictions and challenges to handle them. However, student participation and interaction are crucial factors that we have attempted to investigate. In this paper, we presented a real case study of the emergent transformation to online classes as presented throughout the research, which is different from previous studies because it was not an optional choice.

The findings of this study revealed that, in the aftermath of Corona, most students had a favorable opinion regarding online education. Students appreciated well-structured 
content and included recorded lectures that could be found on the corresponding class team. This article investigated how students experienced remote learning of "Introduction of Web programming lab course" during an emergency transition by assessing their attendance, interactivity, and participation rates as well as their degree of satisfaction.

Many factors affected the process of students' participation and interaction during live meeting class. The availability and stability of an internet connection, the ease of access to teaching media are the main two concerns in the online transferring process and play a vital role in the level of Student' class participation and interaction. However, studies are scarce into the elements that influence students' online course performance. Offline classes are preferred by students, although they are also comfortable with online classes. Microsoft Teams was highly recommended because it is user-friendly, compatible, and easily installed on laptops and mobile devices.

Some changes in teaching methods are required to increase student motivation and reduce distraction, both of which impact their interaction. The diversity in teaching resources (written, video, audio, learning link, pdf file) has a significant impact on the delivery of course material since it can cover students with variant requirements. According to the results, we found s a strong link between student interaction and their academic success. Findings also showed that online education was successfully implemented. However, the interaction of students during meeting class is considered below average. Attendance and performance data were analyzed using correlation analysis and showed a weak positive relationship.

Essential recommendations would play a vital role in improving online students' engagement and interaction and will impact their performance. Based on participants' views about the enhancement process of online classes examined in our case study and endorsed by a general agreement review. The following is a summary of suggested recommendations:

1. Provide more approaches and instructional methods that will have a significant impact on reducing student distraction.

2. Design a well-thought-out course material.

3. Provide additional worksheets and tasks that students can use for self-assessment.

4. Recording video lectures to be a reference to the discussed material.

5. Immediate feedback and instructor-student interaction (e.g., through social media groups).

6. Provide a variety of evaluation procedures (e.g., quizzes, exams, assignments, direct discussions)

\section{References}

[1] Aderibigbe, S., Dias, J., \& Abraham, M. (2021). Understanding issues affecting students' commitment to online discussion forums in undergraduate courses. International Journal of Interactive Mobile Technologies (iJIM), 15(1), 4-23. https://doi.org/10.3991/ijim. v15i01.17939

[2] Alsoud, A. R., \& Harasis, A. A. (2021). The impact of COVID-19 pandemic on student's e-learning experience in Jordan. Journal of Theoretical and Applied Electronic Commerce Research, 16(5), 1404-1414. https://doi.org/10.3390/jtaer16050079 
[3] Aparicio, M., Bacao, F., \& Oliveira, T. (2016). An e-learning theoretical framework. Journal of Educational Technology Systems, 19(1), 292-307.

[4] Byun, S., \& Slavin, R. E. (2020). Educational responses to the COVID-19 outbreak in South Korea. Best Evidence in Chinese Education, 5(2), 665-680. https://doi.org/10.15354/ bece.20.or030

[5] Canós Darós, L., Guijarro Tarradellas, E., Babiloni Griñón, M. E., \& Santandreu Mascarell, C. (2019). Una metodología para evaluar la Competencia Transversal Trabajo en Equipo y Liderazgo. JIDDO. I Jornada de innovación en docencia universitaria para la dirección de organizaciones públicas y privadas, 154-160. https://doi.org/10.4995/JIDDO2019.2019.10190

[6] Chang, C. H. (2011, December). Smart classroom roll caller system with IoT architecture. In 2011 Second International Conference on Innovations in Bio-inspired Computing and Applications (pp. 356-360). IEEE. https://doi.org/10.1109/IBICA.2011.94

[7] Davis, S., Connolly, A., \& Linfield, E. (2009). Lecture capture: Making the most of face-to-face learning. Engineering Education, 4(2), 4-13. https://doi.org/10.11120/ ened.2009.04020004

[8] Gump, S. E. (2006). Guess who is (not) coming to class: Student attitudes as indicators of attendance. Educational Studies, 32(1), 39-46. https://doi.org/10.1080/03055690500415936

[9] Gopal, R., Singh, V., \& Aggarwal, A. (2021). Impact of online classes on the satisfaction and performance of students during the pandemic period of COVID 19. Education and Information Technologies, 1-25. https://doi.org/10.1007/s10639-021-10523-1

[10] Hakala, I., \& Myllymäki, M. (2011). A blended learning solution and the impacts on attendance and learning outcomes. International Journal of Emerging Technologies in Learning (iJET), 6(S2), 42-49. https://doi.org/10.3991/ijet.v6iS2.1658

[11] Honglei, Ren \& Song, You \& Yang, Siyu. (2016). An automated student attendance tracking system based on voiceprint and location. https://doi.org/10.1109/ICCSE.2016.7581583

[12] Korkmaz, S., Gökbulut, B., Yeniasır, M., \& Özbent, A. (2021). Evaluation of changing education system at universities in the pandemic process based on the opinions of faculty members and students. International Journal of Emerging Technologies in Learning, 16(10), 238-254. https://doi.org/10.3991/ijet.v16i10.20795

[13] Lazo, C. M., Errazu, D. V., \& Barroso, J. A. G. (2018). Uso de Twitter en los MOOC: Nuevas formas de interacción juvenil y su influencia en el aprendizaje. Revista Latina de Comunicación Social, 73, 1333-1352.

[14] Midgley, S., \& Resalat, R. (2020). Why distance learning? complete university guide. Retrieved the 15th of June, 2020. retrievable from: https://www.thecompleteuniversityguide. co.uk/distance-learning/what-is-distance learning [Accessed the 20th of September 2021].

[15] Newman-Ford, L., Fitzgibbon, K., Lloyd, S., \& Thomas, S. (2008). A large-scale investigation into the relationship between attendance and attainment: a study using an innovative, electronic attendance monitoring system. Studies in Higher Education, 33(6), 699-717. https://doi.org/10.1080/03075070802457066

[16] Oktavianto, H., Gee-Sern, H., \& Sheng-Luen, C. (2012, June). Image-based intelligent attendance logging system. In 2012 International Conference on System Science and Engineering (ICSSE) (pp. 1-6). IEEE. https://doi.org/10.1109/ICSSE.2012.6257138

[17] Ozaydın Ozkara, B., \& Cakir, H. (2018). Participation in online courses from the students' perspective. Interactive Learning Environments, 26(7), 924-942. https://doi.org/10.1080/ 10494820.2017 .1421562

[18] Pellegrini, M., Uskov, V., \& Casalino, N. (2020). Reimagining and redesigning the postCovid-19 higher education organizations to address new challenges and responses for safe and effective teaching activities. Law and Economics Yearly Review Journal-LEYR, Queen Mary University, London, UK, 9(part 1), 219-248.

[19] Phillips, R., Gosper, M., McNeill, M., Woo, K., Preston, G., \& Green, D. (2007). Staff and student perspectives on web-based lecture technologies: Insights into the great divide.

[20] Phipps, R. (2000). Measuring quality in internet-based higher education: Benchmarks for Success. International Higher Education, 20, 2-4. 
[21] Sadeghi, M. (2019). A shift from classroom to distance learning: Advantages and limitations. International Journal of Research in English Education, 4(1), 80-88. https://doi. org/10.29252/ijree.4.1.80

[22] Saha, D., Mukherjee, I., Roy, J., Sarkar, B., \& Bhattacharjee, R. (2021, February). Attendance and attention monitoring - a perspective in digital pedagogy. In Journal of Physics: Conference Series (Vol. 1797, No. 1, p. 012067). IOP Publishing. https://doi. org/10.1088/1742-6596/1797/1/012067

[23] Samuel, A. (2015). Faculty perception of "presence" in the online environment.

[24] Shimoff, E., \& Catania, A. C. (2001). Effects of recording attendance on grades in introductory psychology. Teaching of Psychology, 28(3), 192-195. https://doi.org/10.1207/ S15328023TOP2803 04

[25] Silva, F., Filipe, V., \& Pereira, A. (2008, October). Automatic control of students' attendance in classrooms using RFID. In 2008 Third International Conference on Systems and Networks Communications (pp. 384-389). IEEE. https://doi.org/10.1109/ICSNC.2008.70

[26] Karakose, T., Yirci, R., \& Papadakis, S. (2021). Exploring the interrelationship between COVID-19 phobia, work-family conflict, family-work conflict, and life satisfaction among school administrators for advancing sustainable management. Sustainability, 13(15), 8654. https://doi.org/10.3390/su13158654

[27] Karakose, T., Yirci, R., Papadakis, S., Ozdemir, T.Y., Demirkol, M., \& Polat, H. (2021). Science mapping of the global knowledge base on management, leadership, and administration related to COVID-19 for promoting the sustainability of scientific research. Sustainability, 13, 9631. https://doi.org/10.3390/su13179631

[28] Karakose, T., Polat, H., \& Papadakis, S. (2021). Examining teachers' perspectives on school principals' digital leadership roles and technology capabilities during the COVID-19 pandemic. Sustainability, 13, 13448. https://doi.org/10.3390/su132313448

[29] Papadakis, S. (2021). Advances in mobile learning educational research (AMLER): Mobile learning as an educational reform. Advances in Mobile Learning Educational Research, 1(1), 1-4. https://doi.org/10.25082/AMLER.2021.01.001

[30] Poultsakis, S., Papadakis, S., Kalogiannakis, M., \& Psycharis, S. (2021). The management of digital learning objects of natural sciences and digital experiment simulation tools by teachers. Advances in Mobile Learning Educational Research, 1(2), 58-71. https://doi. org/10.25082/AMLER.2021.02.002

\section{Authors}

Duha Qutishat works as an instructor the Department of Information Technology, Faculty of Prince Al-Hussein Bin Abdallah II For Information Technology, The Hashemite University, P.O. Box 330127, Zarqa 13133, Jordan Email: Duha@hu.edu.jo

Randa Obeidallah works as an instructor the Department of Computer Infor mation System,Faculty of Prince Al-Hussein Bin Abdallah II For Information Technology, The Hashemite University, P.O. Box 330127, Zarqa 13133, Jordan Email: randa.ali@, hu.edu.jo

Yasser Qawasmeh works as an instructor the Department of of Computer Science and Applications,Faculty of Prince Al-Hussein Bin Abdallah II For Information Technology, The Hashemite University, P.O. Box 330127, Zarqa 13133, Jordan Email: Yasser@hu.edu.jo

Article submitted 2021-09-25. Resubmitted 2021-11-22. Final acceptance 2021-12-17. Final version published as submitted by the authors. 